\title{
What Is Inquiry-Based Learning?
}

\section{Dana C. Ernst, Angie Hodge, and Stan Yoshinobu}

“The objective in mathematics is not to obtain the highest ranking, the highest 'score,' or the highest number of prizes and awards; instead, it is to increase understanding of mathematics (both for yourself, and for your colleagues and students), and to contribute to its development and applications. For these tasks, mathematics needs all the good people it can get."

Abstract. Inquiry-based learning (IBL) can manifest itself differently in various classroom settings. Historically, IBL was most often implemented in proof-based courses. Lately it can be found in university mathematics classrooms at all levels. This paper provides an overview of IBL followed by three detailed examples of what IBL can look like in particular classroom settings.

\section{Communicated by Harriet Pollatsek}

\section{Introduction}

The main goal of this article is to address the question, "What is inquiry-based learning today?" IBL is a form of active learning in which students are given a carefully scaffolded sequence of mathematical tasks and are asked to solve and make sense of them, working individually or in groups. In this article, we describe the core principles of IBL and provide three specific but representative examples

Dana C. Ernst is assistant professor of mathematics at Northern Arizona University. His e-mail address is dana. ernst@nau. edu.

Angie Hodge is associate professor of mathematics and Dr. George Haddix Community Chair of Mathematics Education at the University of Nebraska Omaha. Her e-mail address is amhodge@ unomaha. edu.

Stan Yoshinobu is professor of mathematics at Cal Poly San Luis Obispo. His e-mail address is styoshin@calpoly.edu.

For permission to reprint this article, please contact: reprint-permission@ams .org.

DOI: http://dx.doi.org/10.1090/noti1536

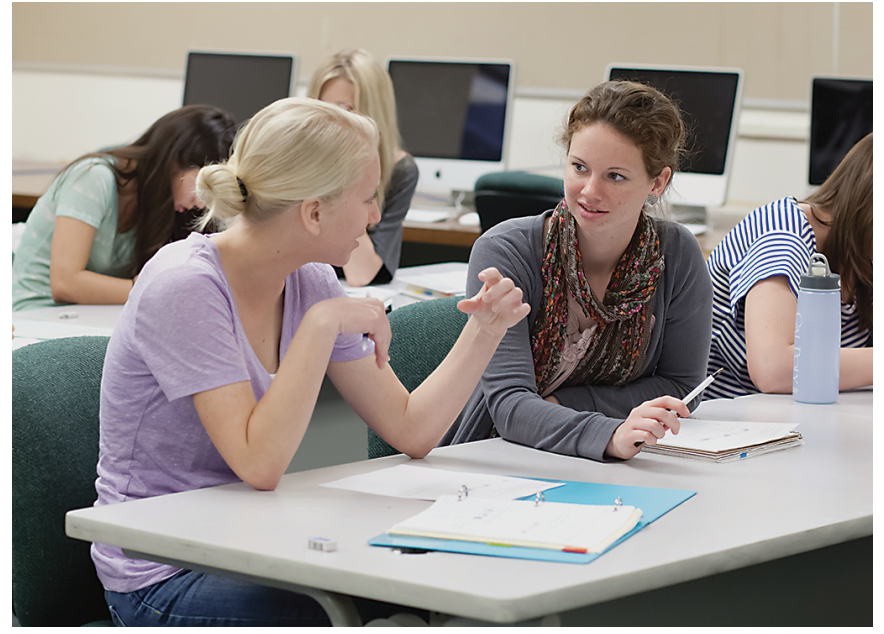

Prospective elementary school teachers at Cal Poly San Luis Obispo discuss problems and prepare to present their work.

of IBL classrooms from our perspective: upper-division proof-based mathematics courses, the calculus sequence, and mathematics for elementary teachers. Active, student-centered pedagogies such as IBL exist in a dynamic landscape, so describing teaching methods that are constantly evolving is a challenging and slippery task. We are still developing and trying to understand the variety of IBL methods, when and where they are applicable, and identifying best practices. Here we share some of the commonly used examples and core ideas that drive instructor decisions. 
Thinking, experimenting, asking questions, working with ideas, and all that goes into building knowledge are what we aim for as mathematicians. We share these objectives broadly, no matter what we teach or how. Indeed, active learning strategies have gained significant endorsements in recent years, most notably by the Conference Board of the Mathematical Sciences this year [2]. Although a discussion of the evidence in support of IBL is beyond the scope of this article, much work has been done on the effectiveness of IBL. Readers wanting to learn more about this research can start with David Bressoud's overview of IBL [3] and Kogan and Laursen's work [4].

\section{Core Principles and the Big Tent}

IBL is a form of active learning that comes in many shapes and sizes. Common to these many forms of IBL are two principles, the "twin pillars" that education research [5] has shown to be at the core of most implementations of IBL:

1. Deep engagement in rich mathematics.

2. Opportunities to collaborate (in some form).

Deep engagement in rich mathematics is the first pillar and is an encompassing phrase, indicating that students are actively and intentionally working on challenging (to them) mathematics problems. It means that the students themselves do a significant portion of the development of mathematical ideas, which are more sophisticated than rote skill-level exercises (although rote skill work is valued and developed). Typically, students do not know the answer or method ahead of time, and the questions generally require grappling with mathematical ideas before arriving at a solution to the problem.

Collaboration is the second pillar and can come in many forms. The most common is structured group work. Students are asked questions and work collaboratively as a team to think through mathematical ideas. Students' thinking benefits from verbalizing their thoughts, and, in doing so, students learn how to effectively communicate mathematics orally and in written form.

Collaboration can take other forms besides group work. For example, in an upper-division course with a focus on proof, students often present their proofs to the entire class. The class peer-reviews the proof, discussing its features such as validity, techniques, and coherence. Hence, class discussion is a class-wide collaboration, moderated by the instructor. In this case the class works together to validate and understand the meaning of proof.

The existence of the many varieties of IBL is a natural result of the broad and changing landscape of college mathematics education. Class size, prior experiences of students, course topic, and other factors significantly affect an instructor's choices when implementing IBL. An instructor's level of skill and experience with IBL also plays a role in teaching decisions about the structure of a class. These factors and more combine to suggest that varied and disparate factors influencing teaching decisions have given rise to a great variety of IBL under one "big tent."
Thus IBL classes can look very different and yet still have in common the twin pillars of deep engagement in rich mathematics and opportunities to collaborate.

\section{IBL Example 1: Upper-Division, Proof-Based Courses}

Proof-based courses are a natural setting for IBL. In fact, there is a long tradition of using IBL in these courses, where class size and content pressure are typically minimized when compared to other courses we teach. Students in IBL proof-based courses are asked to develop the fundamental concepts and to produce the proofs of the important theorems. This may require abandoning a traditional textbook in favor of a customized sequence of tasks that meets the students where they are mathematically and is designed to guide them on a journey of mathematical discovery. As opposed to completing exercises after an instructor has covered the relevant material, students decipher definitions, explore examples, make conjectures, and prove theorems. The intention in IBL courses is for the students to make sense of and solve core exercises and problems as they progress through the course.

After each class meeting, students are assigned problems to work on outside of class. Each student is expected to come to the next class meeting prepared to present and discuss their proposed solutions or proofs. In our experience, a typical assignment will consist of roughly 5-15 problems. Each batch of problems is meant to do some subset of the following:

- Introduce a new topic

- Develop intuition about a concept

- Synthesize ideas from a few concepts

- Make a conjecture

- Prove a theorem

- Get practice doing routine or non routine problems

On a typical day, most of the class time is devoted to student presentations. The purpose of the presentations is to drive classroom discussion. In many cases, the most productive presentations are ones that are interestingly wrong, since this creates opportunities for students to engage in meaningful discourse. Implementation of the student presentations can take several forms, such as these scenarios:

1. An individual student acts as a spokesperson for her or his small group and presents a group's proposed solution.

2. An individual presents her solution.

In practice, an instructor is likely to utilize a mixture of both styles when managing student presentations throughout the semester, adjusting for various factors such as difficulty of the material.

The first scenario can play out as follows. Suppose a class of thirty students has an assignment consisting of ten problems that is due the next class meeting. The assignment includes a mixture of exercises related to the relevant concepts and proofs of related theorems. Students are expected to answer all of the problems 
to the best of their ability before the start of class. Collaboration of peers is encouraged, but students should write up their own solutions independently. As students enter the classroom, they each grab a colored marker pen that they are encouraged to use to annotate their assignment during class. The purpose of the colored pen is so that the instructor can distinguish the work that a student did before class from the work done during class.

Students are arranged in small groups and each group is assigned one of the problems. The group's task is to arrive at consensus on a solution or proof for their assigned problem. The first phase of class (roughly 10-20 minutes of a 50-minute class) is devoted to small group discussion. In a classroom with ample board space, the small groups can spread out around the room and write their solutions on the board. Otherwise, each group can write their solution on a sheet of paper that can later be displayed using a document camera. While the groups are working, the instructor can float around the classroom listening to student conversation, providing gentle nudges and encouragement as needed, and assisting when necessary.

The next phase of class provides an opportunity for a spokesperson for each group to present their proposed solution, or possibly partial solution. During each presentation, students in the audience are asked to validate the ideas presented. It is vital that the classroom environment provide a safe atmosphere where students are comfortable sharing and critiquing ideas respectfully.

One of the main roles for IBL instructors is to manage class discussions, ensuring that discussions are fruitful. The skills required to do this are essential and are distinct from lecturing skills. IBL instructors face a range of in-class decisions when managing discussions. When students get stuck or need assistance when presenting, IBL instructor options include (but are not limited to) tabling a discussion until the next class meeting; writing a lemma on the board, providing a middle step for the current problem; asking students to work in small groups to offer suggestions; and offering instructor hints or insights. Choices depend on a variety of factors and are situational. Each strategy has strengths and weaknesses, and choices are based on maximizing student learning.

\section{IBL Example 2: Calculus}

The calculus sequence stands as either a gateway or a gatekeeper for many of the STEM disciplines. Bressoud, Rasmussen et al. in the Mathematical Association of America's Calculus Study determined that there are seven common characteristics of successful calculus programs. Among those seven are "construction of challenging and engaging courses" and "use of student centered pedagogies and active learning strategies." IBL addresses both of these characteristics but is often dismissed in the calculus sequence due to time and coverage constraints. We offer a sample of useful IBL strategies for calculus courses. Some or all of these strategies could be used for any lower-division mathematics courses, where class sizes are often large and one must cover a certain amount of material over the semester. In this section we describe three strategies: student presentations, IBL worksheets, and TACTivities.

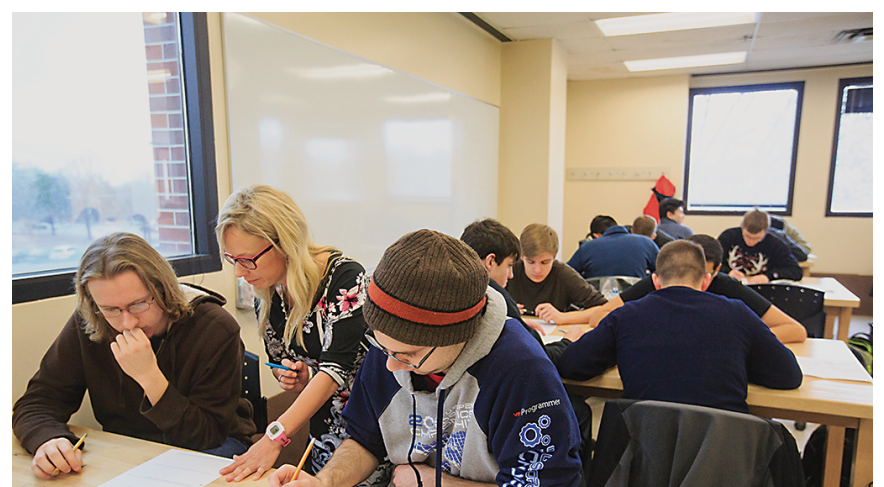

Calculus II students at the University of Nebraska Omaha engage in active learning worksheets.

Everything said about presentations and group work in a proofs course also applies to the calculus sequence.

Presentations. A typical calculus course often begins with the instructor answering student homework questions. In an IBL calculus class, homework is still addressed, but instead of having students watch an instructor write out solutions to homework problems, we can engage the students in this process. Allow the students to come to class and post problems on the board that they would like to see worked out. If they do not have any suggestions, then have a handful of problems that you want to be sure all students have thought about carefully. Put these problems on the board with space for solutions to be written out. Instead of the instructor writing the answers, have the students write out their solutions (or even their partial solutions). Then have the students present these solutions to the class. The instructor moderates the discussions and assists with communication of the ideas. Taking time to have students present their proposed solutions helps develop many important communication skills as well as engaging students in the learning process.

IBL worksheets. While teaching new material, carefully designed day-to-day tasks will help ensure material is still covered that is required for the course. To create worksheets (or problem sets) to take the place of lectures, one must determine what the students can figure out on their own and what they will need guidance on. For instance, students may not be able to discover the Fundamental Theorem of Calculus on their own, but they may be able to develop intuition about why it works with a carefully selected set of steps guiding them. They may also need one example showing them how to use the Fundamental Theorem of Calculus, but not all of the steps or "tricks." IBL calculus worksheets often have problem sets that are designed so that the students have to figure out the ideas themselves once they have an understanding of the basics. Fill-in-the-blank two-column proofs have also been used successfully in calculus courses to include rigor without the instructor providing the entire proof. For example, one may provide the step in the proof and ask for the reason from the student. One may also give a hint in one column and have the student complete the step. This fillin-the-blank method also works well with new concepts, when students need hints/scaffolding to complete the 
first problem on the worksheet. Subsequent problems in the set have few or no hints.

Tactile learning activities (TACTivities) are another way to engage calculus students. These activities are ones in which there are literally moving pieces. They can be used to introduce a new topic, but they are even better for reviewing or enhancing skills without "drill and kill" worksheets. For example, ${ }^{1}$ students may be given graphs of several functions and their derivatives. These graphs are on small cards, usually laminated or printed on card stock. The students only have graphs of the functions, without equations. The students then have to match each function graph to its derivative graph by sorting out these cut-out pieces. Another type is a "domino TACTivity." The dominoes are great for reviewing concepts. For example, students are given a set of cards that look like dominoes with one half of each domino having an integral on it and the other half having an antiderivative on it. The cards are mixed up and students must sort the cards so that each integral is matched with its corresponding antiderivative. Once the cards make a complete "circle" the activity is complete. This TACTivity works for anything that comes in pairs.

Worksheets/problem sets and TACTivities are designed to be completed in groups of two to four students. Each student fills out her/his worksheet as notes for the course to encourage both collaboration and individualized learning. Students enjoy working together and often bond with other students while discussing/arguing peacefully about how to solve hard problems or complete the TACTivities. Student presentations can be given on problems that students are having trouble with or to help students see multiple solution paths.

\section{IBL Example 3: Mathematics for Elementary Teachers}

Elementary school teachers teach mathematics to our children, developing the foundational knowledge of mathematics young children carry with them the rest of their lives. Future elementary school teachers require a deep, sophisticated understanding of school mathematics and development of children's mathematical thinking. IBL math courses provide a framework for instructors to accomplish the critically important learning objectives for prospective elementary school teachers. The example below is one of a family of IBL courses for future elementary school teachers.

The main components of this IBL math course for elementary teachers are

1. Authentic IBL mathematical experiences

2. Readings about problem solving and learning school mathematics

3. Video lesson study and projects

The most important component is providing an authentic IBL mathematical experience. In courses for future elementary school teachers, students redevelop fundamental mathematical structures that children must

\footnotetext{
${ }^{1}$ Many examples of active learning materials for calculus, including TACTivities, can be found at math. colorado. edu/activecalc.
}

learn from an advanced, teacher's perspective. Future teachers remember how to do arithmetic, but they may not fully understand why things work the way they do. Courses for future elementary teachers can illuminate the deeper ideas and mathematical structures via IBL methods, where students are given problems involving learning how and why school mathematics works the way it does.

Example: Students investigate why an algorithm for comparing fractions works. The algorithm is to find which fraction is larger, $a / b$ or $c / d$, by cross-multiplying and comparing $a d$ versus $b c$. The larger side indicates the larger fraction. Students start by studying equivalent fractions and more generally the notion of equivalence (that two objects can be equal yet have nonidentical expressions). As they work through the set of problems, key ideas appear, and students find a pathway of ideas and techniques that enables them to answer the original question, eventually justifying the algorithm as really a shortcut to comparing numerators of fractions with the same denominator.

To a mathematician this fact may be obvious. To future teachers, it likely is not obvious. Many of them have only seen or memorized the algorithm. It is hard enough to teach well something you understand, much less something you have only memorized.

IBL math activities are the heart of the class and comprise the bulk of the class time and assignments. To explicitly connect their mathematical work to school mathematics, students are assigned readings, and a few classes are used for video lesson study. What this involves is studying videos of children doing mathematics and learning how the mathematics, student thinking, and teaching decisions are interconnected. These videos present children's mathematical thinking in an inquiry-based learning environment, where children are given mathematical tasks, work on them, and share their findings. The prospective teachers evaluate the mathematical thinking in evidence in the videos and how tasks were given to students.

\section{How to Get Involved or Get Started}

Learning to use IBL is nontrivial. The start-up time and pitfalls for beginning IBL instructors can be significant. Other factors in IBL teaching include obtaining student buy-in, building a safe learning environment, managing group work, making changes in assessment, managing the classroom when students are presenting material, harnessing mistakes or productive failure, and creating appropriate mathematical tasks. Learning these is best done with support.

The IBL community supports both new and experienced IBL instructors. The IBL community is open to everyone and there exist several ways to join the community, 
including the Academy of Inquiry Based Learning, ${ }^{2}$ programs by the Educational Advancement Foundation, ${ }^{3}$ the Discovering the Art of Mathematics project, ${ }^{4}$ Journal of Inquiry-Based Learning in Mathematics, ${ }^{5}$ and the recently formed IBL Special Interest Group of the Mathematical Association of America. ${ }^{6}$

Teaching is a profession with specific skills and practices that need to be learned and developed. Just as research shows there is no math gene, likewise there is no teaching gene. Mathematics instructors at all levels can learn to engage students in the process of doing mathematics, and we invite those who are interested to join us and give IBL a try!

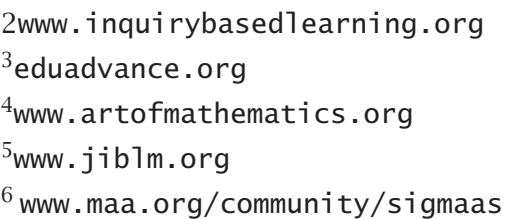

\section{References}

[1] Terence TaO, Does One Have to Be a Genius to Do Maths? Retrieved from https://terrytao.wordpress.com /career-advice/does-one-have-to-be-a-genius-to -do-maths.

[2] Conference Board of the Mathematical Sciences Active Learning Statement. Retrieved from www.cbmsweb.org /Statements/Active_Learning_Statement.pdf.

[3] DAVID BRESSOUD, Evidence for IBL. Retrieved from 1aunchings . blogspot. com/2015/10/evidence-for-ib1 . htm1 .

[4] M. KOGAN and S. LAURSEN, Assessing long-term effects of inquiry-based learning: A case study from college mathematics, Innov. High Educ. 39 (2014):183-199.

[5] S. LAuren, M:-L. Hassi, M. Kogan, A:-B. Hunter, and T. Weston, Evaluation of the IBL Mathematics Project: Student and Instructor Outcomes of Inquiry-Based Learning in College Mathematics. Retrieved from www. colorado. edu/eer /research/documents/IBLmathReportALL_050211.pdf.

\section{Photo Credits}

Photo of prospective elementary school teachers is courtesy of Stan Yoshinobu.

Photo of Calculus II students is courtesy of the University of Nebraska Omaha.

\section{ABOUT THE AUTHORS}

Dana C. Ernst was the 2016 recipient of the MAA Southwest Section Teaching Award and has been incorporating IBL in his teaching since 2009. In addition to mathematics and teaching, his passions include cycling and rock climbing.

Angie Hodge is the PI of an NSF Noyce grant to develop expertise in IBL in pre-service mathematics teachers. She travels all over the world to run ultramarathons, including the Leadville 100-mile run.

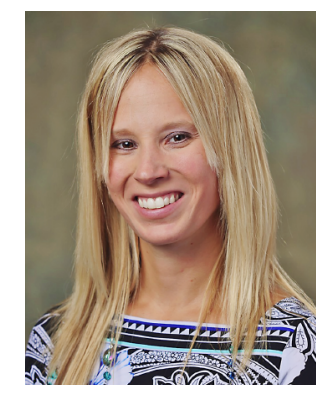

\section{Angie Hodge}

Stan Yoshinobu is director of the Academy of Inquiry Based Learning. He has taught a variety of courses via IBL for more than a decade. Away from his office he enjoys spending time with his family, photography, travel, and hiking.

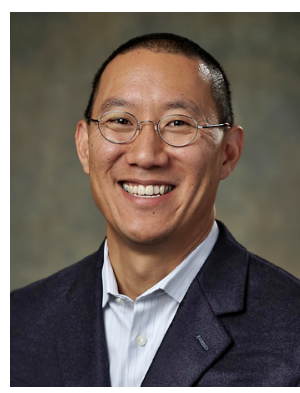

Stan Yoshinobu 